\title{
Variation in Polyamine Content among 12 Pollinated Wheat Genotypes under Drought Stress Condition
}

\author{
Mahdi Seyedsalehi' ${ }^{1}$, Parisa Sharifi ${ }^{*}$, Ombretta Paladino ${ }^{3}$, Gassan Hodaifa ${ }^{4}$, \\ Elba C. Villegas ${ }^{5}$, Randa M. Osman ${ }^{6}$
}

\begin{abstract}
${ }^{1}$ Department of Environmental Engineering, Science and Research Branch, Islamic Azad University, Tehran, Iran
${ }^{2}$ Department of Agronomy, Faculty of Agriculture, Urmia University, Urmia, Iran

${ }^{3}$ Department of Civil, Chemical and Environmental Engineering, Università di Genova, Genoa, Italy

${ }^{4}$ Department of Molecular Biology and Biochemical Engineering, Chemical Engineering Area, University of Pablo de Olavide, Seville, Spain

${ }^{5}$ Laboratory of Function-Structure and Protein Engineering, Center for Research on Biotechnology, Autonomous

University of Morelos State (UAEM), Cuernavaca, Mexico

${ }^{6}$ Department of Chemical Engineering and Pilot Plant, National Research Centre, Cairo, Egypt

Email: M.s.salehi1365@gmail.com, ^sharifi_parisa_phd@yahoo.com,paladino@unige.it, ghodaifa@upo.es, elbav@uaem.mx,

randa.osman@yahoo.com
\end{abstract}

How to cite this paper: Seyedsalehi, M., Sharifi, P., Paladino, O., Hodaifa, G., Villegas, E.C. and Osman, R.M. (2017) Variation in Polyamine Content among 12 Pollinated Wheat Genotypes under Drought Stress Condition. Open Journal of Geology, 7, 10941109.

https://doi.org/10.4236/ojg.2017.78073

Received: July 19, 2017

Accepted: August 12, 2017

Published: August 15, 2017

Copyright $\odot 2017$ by authors and Scientific Research Publishing Inc. This work is licensed under the Creative Commons Attribution International License (CC BY 4.0).

http://creativecommons.org/licenses/by/4.0/

\section{(c) (i) Open Access}

\begin{abstract}
The present work aims to study the drought stress effects on polyamine content and its relationship with growth and development in seeds, during cell division (from the beginning and until 17 days after pollination) and grain filling (until reaching the physiological maturity) stages. Factorial experiment based on Randomized Complete Block (RCB) design was carried out with three replications. Two factors of the experiment were considered: the level of irrigation (irrigation without and with drought stress during cell division stage and with drought stress during grain filling stage) and the level of wheat genotype (drought-resistant, semi-resistant and sensitive genotypes). As control treatment, soil moisture content of the field was considered. For droughtstress treatment, the $50 \%$ of the soil moisture content in control treatment was established. According to the experimental results, Putrescine content value is higher in control treatment which develops seeds of drought-resistant genotypes than that are registered for semi-resistant and sensitive genotypes. Both drought stress treatments induced significant rises in putrescine amount in the different genotypes of the study. The rises of putrescine content in sensitive and semi-resistant genotypes, however, were higher than in resistant ones, and the highest rise in putrescine content appeared in manning semi-resistant genotype during the stage of grain filling (27 days after pollination). Exerting
\end{abstract}


drought stress in both stages of cell division and grain filling led to significant increase in spermine and spermidine contents of developing seeds of entire genotypes of the study. The highest spermidine content during grain filling stage occurred in sensitive genotypes of Shark and Tevee's, and the lowest occurred in semi-resistant genotype of Sabalan. The highest spermine content during cell division stage, though, happened in semi-resistant genotype of manning. In fact, spermine and spermidine act as analogous to plant hormones such as Auxin and Cytokine, or they cooperate with these hormones in order to take a role in cell division regulation of developing wheat seeds and development of sink strength. They, additionally, stabilize the cell division process of developing seeds under drought condition. According to the findings of the study, manning semi-resistant genotype is capable of having a high grain yield under drought condition by reason of reserving high amounts of polyamines.

\section{Keywords}

Polyamines, Drought, Wheat, Randomized Complete Block (RCB)

\section{Introduction}

Drought, every year, jeopardizes the potential successful outcome of agricultural crops in Iran and many other countries around the world with varying degrees severity. Iran is located on the desert belt of the earth, and with the exception of some small regions in the vicinity of Caspian Sea coasts, Elburz and Zagros Mountains, the whole country has arid or semi-arid climate. Hence, drought stress is considered as one of the major threats of wheat production of the country, and owing to the recent lasting droughts, it has attracted much more attention.

According to Lie et al. [1], water deficiency affects plant-water relation in molecules, cells and subcellular compartments of plants. Dryness closes the pores of the plant and, as a result, reduces its photosynthesis which results in reduction in growth and development of the plant [2]. It is worth mentioning that the stomatal conductance is regulated by soil moisture content. A combination of endogenous and exogenous factors also influences on the stomatal conductance as well [3]. The activity of the assimilation carbon enzyme and the enzymes affecting adenosine triphosphate synthesis coordinates with the moisture content of the soil [2].

One of the key elements which disrupts the growth and development of the plant under drought stress condition is producing reactive oxygen species in organelles such as mitochondrion, chloroplast and peroxisome [2] [4]. Excessive production of reactive oxygen species results in membrane lipid peroxidation and protein degradation of enzymes and nucleic acids [5].

In plants a great number of bio-chemical and physiological processes of mo- 
lecules, tissues and organs, and eventually, the plant itself, play roles in the tolerance of drought stress condition. When a plant loses water under drought stress, for instance, its resistance is against that is shown by shutting the pores of the plant. In this situation, also the root system tries to absorb more water by taproots and fibrous roots [3]. In this regard, substances such as salicylic acid, melatonin and abscisic acid have a principal role in the tolerance of the plant to drought. Controlling reactive oxygen species via enzymatic and non-enzymatic antioxidant systems, cell membrane stability and modification of the stress proteins are in the group of mechanisms which play vital role in drought stress tolerance [6].

Polyamines are hormone-like compounds whose concentration in plant cells is higher than the concentration of plant growth regulators such as abscisic acid (ABA), cytokinins (CK), auxins (IAA) and gibberellins (GA). Millimolar concentrations of polyamines are essential for producing biological response, and they are valuable polycations which take roles in different stages of plant growth and development. In fact, spermidine (Tri-amine), spermine (Tetra-amine) and their precursor, putrescine (Di-amine), are considered as the foremost polyamines. On the other hand, polyamines acts as growth regulators, are capable of intervening in numerous domain of growth and development processes such as cell division fertilization, embryogenesis, morphogenesis, root development, flowering process, fruit maturity, senescence delaying, membrane stability, stress tolerance and free radicals scavenging activity [7] [8].

Plants resistance against non-biological stresses such as drought and salinity could be improved by using polyamines. This became a noteworthy topic in the past few years, and it has reported their function as oxygen free-radicals deactivators [9] [10]. The anti-oxidant feature of polyamines, in effect, might be associated with controlling the NADPH Oxidase Enzyme and inhibiting the accumulation of superoxide radicals [11]. Different actions have polyamines in terms of relieving stress. During emergence of drought stress condition, particularly spermidine is accumulated in wheat seedlings two or three times more than that at normal condition. The amount of polyamines drops after afresh and regular irrigation, and reaches the approximate amount that existed prior to stress exertion [12]. In addition, polyamines play a substantial role in preserving the integrity and stability of cytoplasmic membrane, nucleic acids and cellular organelles during drought stress condition [13]. There has found a positive correlation in rice between polyamines accumulation and growth of the plant during the presence of drought stress [14]. Also, it has been expressed in various researches that polyamines play a key role in regulating defense responses of plants to different environmental stresses including stresses stem from presence of heavy metals [15] [16] oxidative stress agents [17], drought condition [18], salinity stress [19] and freezing stress [20]. It has been reported that treatments of polyethylene glycol 6000 bring about a significant rise in the spermidine and spermine contents in tolerant wheat variations, whereas in the sensitive variations the Putrescine content increases significantly [21]. 
The present work aims to study the drought stress effects on polyamine content and its relationship with growth and development in seeds, during cell division (from the beginning and until 17 days after pollination) and grain filling (until reaching the physiological maturity) stages. Factorial experiment based in Randomized Complete Block (RCB) design was carried out with three replications. Two factors of the experiment were considered.

\section{Material and Methods}

\subsection{Methodology}

This work was carried out in Agriculture Department of Higher Education Center of Shahid Bakeri, Urmia University, Urmia, Iran.

A factorial experiment in Randomized Complete Block (RBC) design was carried out using 3 replications. Two factors were studied, the level of irrigation (irrigation without drought stress, with drought stress from the beginning of pollination until 17 days after, with drought stress from the day 17 after pollination until the physiological maturity) and the different genotypes (resistant genotypes of PTZ NISKA/UT1556-170//UNKNOWN, TRK13/KAUZ, Dogu88/Ghafghaz 7, Sardari HR-86, Daric 98-95 and ZHONG 25792; semi-resistant genotypes of Manning/Sdv1/Dogu8, Sabalan, Rasad and DH-2049-3; sensitive genotypes of SHARK and TEVEE'S'//CROW/VEE'S).

According to Ehdaie [22], fulfilling 50 percent of pollination process in spikes of every single genotype was considered as the pollination time. Genotypes planting was based on 1000 kernel weight, seed vigor and sowing density of 400 seeds per square meter, and carried out in early November, after the tillage and cultivation in late September, 2014.

Soil analysis revealed that there was no need for phosphorus or potassium fertilizers. Only, nitrogen fertilizer required. Thus, $260 \mathrm{~kg}$ of urea was applied per hectare in three stages, planting, tillering and before flowering.

After the experiment (standard and stresses applied) spikes were randomly harvested and wheat grains were taken out using a forceps, wrapped in aluminum foil and placed in liquid nitrogen. Thereafter, samples were taken out from liquid nitrogen and kept at $-70^{\circ} \mathrm{C}$.

\subsection{Determination of Polyamine Contents (Putrescine, Spermine and Spermidine)}

The method employed by Ma [23] was adopted for polyamines measuring. Thus, $0.2 \mathrm{~g}$ of leaf tissue of collected samples was rinsed in 0.2 molar solution of perchloric acid at $4^{\circ} \mathrm{C}$ and kept in cold storage room during 1 hour. Then, samples were centrifuged at $18,000 \mathrm{rpm}$ for 20 minutes, and the supernatant that contains polyamines was conveyed to small vials.

$50-100 \mu \mathrm{L}$ of the solution was saturated by $200 \mu \mathrm{L}$ of sodium carbonate, and mixed with $400 \mu \mathrm{L}$ of dansyl chloride. Samples were vortexed and kept in dark at $60^{\circ} \mathrm{C}$. Then, $100 \mathrm{mg} / \mathrm{L}$ of proline was added. After 30 minutes, $500 \mu \mathrm{L}$ of toluene 
was added and vortexed again. The organic phase formed was separated and drying in Liofilizar. The precipitates were vortexed in $1 \mathrm{~mL}$ of Ethanol and diluted 1 to 5 .

High-Performance Liquid Chromatography (HPLC) with a C18 column was employed to measure organic compounds. For HPLC calibration, water and methanol were utilized as solvent. HPLC grade of 60 - 95 percent of methanol for the first 23 minutes, 100 percent in $23-28$ and 60 percent of methanol from 28 until 32 with flow rate of $1 \mathrm{~mL} / \mathrm{min}$ were operated. Fluorescence detector at excitation wavelength of $365 \mathrm{~nm}$ and emission wavelength of $510 \mathrm{~nm}$ was used. Subsequent, spermidine, spermine and putrescine were injected and area under every polyamine curve was calculated. Then, standard curve and the relationships between concentration and area under the curve were established.

Finally, for yield determination, 1 square meter was harvested from every plot after removing the margins in maturity stage of the crops. For component yields calculation including kernel per spike and 1000 kernels weight, randomly 10 bushes were selected as sample and the calculation done.

\subsection{Calculation Methods}

Statistical calculations were made using SPSS software (version 19), and mean comparisons were carried out using Duncan Method for a significance level of 0.05 .

\section{Result and Discussion}

\subsection{Variation in Yield and Yield Components}

Variance analysis revealed that kernel per spike variance, 1000 kernels weight and grain yield characteristics of genotypes of the study have statistically significant differences at the 0.05 level. Drought stress treatment, in addition, had a significant effect on the kernel per spike, 1000 kernels weight and the grain yield characteristics at 0.05 level of significance (Table 1 ).

The significant interaction effect between drought stress treatment and genotype on the grain yield ascertained that exerting experimental drought stress brings about a decrease in the grain yield of genotypes of the study. Comparing

Table 1. Analysis of variance of the effect of drought stress after pollination stage on yield and yield components.

\begin{tabular}{ccccc}
\hline S.O.V & df & Grain Yield & Grains per Spike & 1000 Grains Weight \\
\hline Genotype & 11 & $11,556.41^{*}$ & $160.20^{*}$ & $386.08^{\star}$ \\
Drought & 1 & $1,703,590.55^{\star}$ & $196.61^{*}$ & $1950.47^{\star}$ \\
Genotype $\times$ Drought & 11 & $8787.76^{\star}$ & $52.03^{\star}$ & $31.38^{\star}$ \\
Error & 120 & 2.70 & 3.34 & 2.85 \\
Variation Coefficient & - & 30.33 & 11.92 & 22.12 \\
\hline
\end{tabular}

${ }^{\star}$ Significant at 0.05 level. ${ }^{\text {ns }}$ Not significant. 
the means, additionally, displayed that the maximum and the minimum grain yield under drought stress condition belonged to genotypes of TEVEE'S'// CROW/VEE'S $\left(173 \mathrm{~g} \cdot \mathrm{m}^{-2}\right)$ and Manning/Sdv1/Dogu88 $\left(221 \mathrm{~g} \cdot \mathrm{m}^{-2}\right)$, respectively (Figure 1).

Comparing the mean of interaction effect between drought stress and genotype on kernel per spike characteristic revealed that the highest amount of kernel per spike belonged to genotype TRK (39/1), and the lowest amount under drought stress condition appeared in genotype Shark (28), Figure 2. Result of interaction between drought stress and genotype on 1000 kernel weight characteristic indicated that the maximum 1000 kernel weight under drought condition belonged to genotype Manning/Sdv1/Dogu88 (38.3 g), and the minimum belonged to drought-sensitive genotypes of SHARK (8/23 g) and TEVEE'S'// CROW/VEE'S (25 g), Figure 3.

Emergence of drought stress after pollination induces drop in grain yield, which probably happens due to the drop in nutrient storage and the storage capacity of grains [24]. The drop in 1000 kernel weight under the drought stress condition after pollination happened more severely in comparison with other

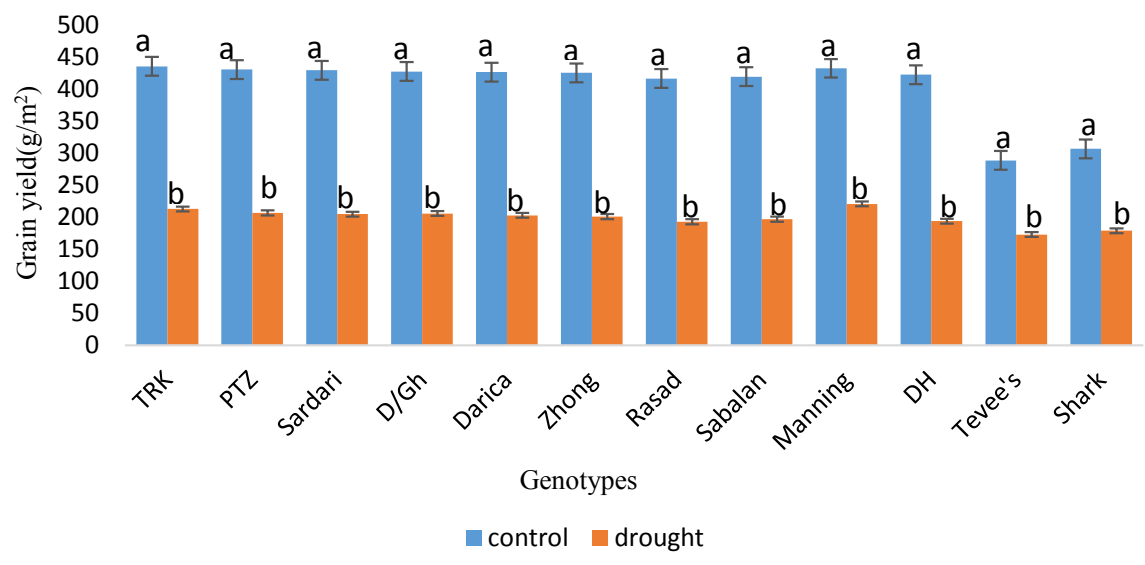

Figure 1. The mean comparison of interaction effect between genotype and moisture regime on grain yield characteristic.

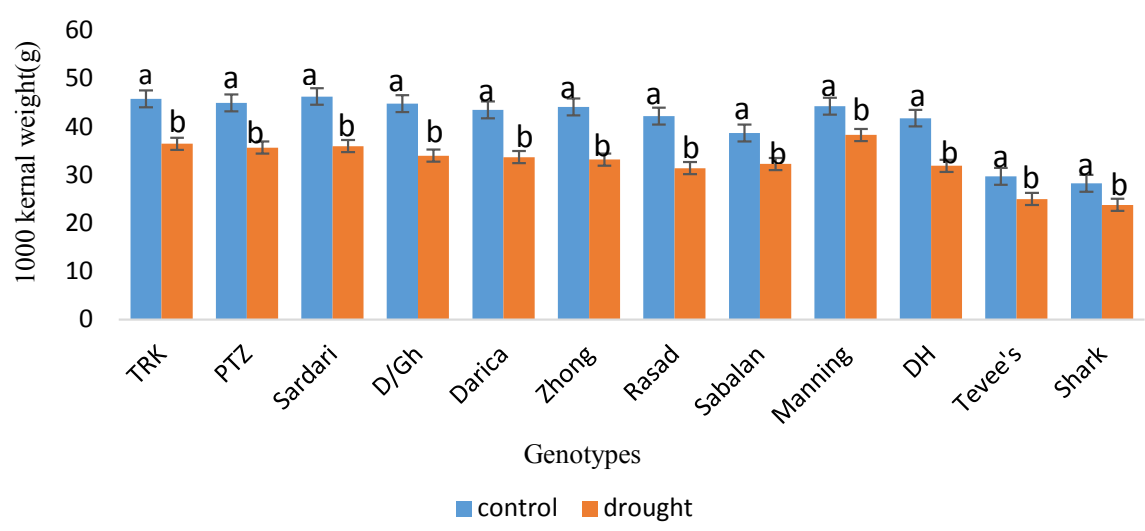

Figure 2. The mean comparison of interaction effect between genotype and moisture regime on 1000 kernel weight characteristic. 


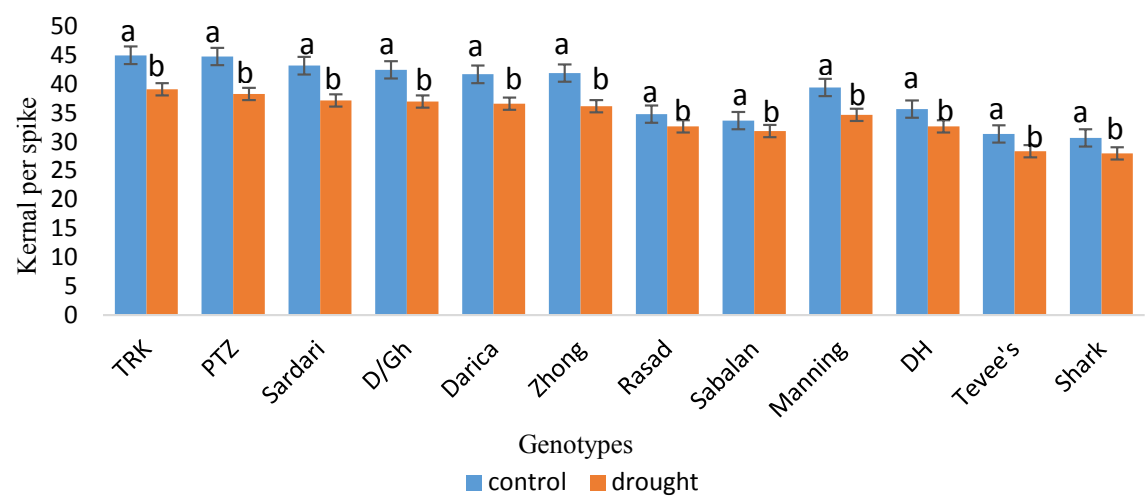

Figure 3. The mean comparison of interaction effect between genotype and moisture regime on kernel per spike characteristic.

two yield component, i.e. kernel per spike and spike per area unit, by reason of not fulfilling the required photosynthetic substances of grains, and this drop in the yield component lead to much more drop in the grain yield [25]. The semiresistant genotype of Manning/Sdv1/Dogu88 obtained higher grain yield compared with the other genotypes, owing to the higher 1000 kernel weight component under drought stress condition after pollination.

\subsection{Variation in Polyamines Contents}

Results from analysis of variance for spermidine characteristic revealed that there is significant difference at 0.05 level among genotype and drought stress treatments and their interaction (Table 2). Contrasting the means of interaction between drought stress treatments and genotypes of the study led to believe that exerting drought stress and adding to its intensity in every phase of wheat plant development lead to continuous rise in spermidine content in various genotypes of the study (Figure 4).

There were dissimilar amounts for spermidine content of studied genotypes under drought stress after pollination. It was not observed any significant difference among drought-resistant genotypes (TRK, PTZ and Sardari) during the second and third phases of sampling, i.e. 17 and 27 days after pollination. There was a continuous and significant increase, however, in the spermidine contents of drought-sensitive genotypes.

The highest amount of spermidine content in the last phase of sampling (27 days after pollination) happened in drought-sensitive genotypes of Shark and Tevee's, and the lowest Spermidine content belonged to semi-resistant genotype of Sabalan. Comparing the different phases of sampling revealed that there was a significant difference in the spermidine content of different genotypes. Additionally, results showed that under the typical irrigation condition, resistant and semi-resistant genotypes of the study had the lowest spermidine content and the sensitive-genotypes had the highest amount (Figure 4).

The higher concentration of spermidine during the growth of developing seeds in all genotypes of the study revealed a similar behavior to that of sper- 


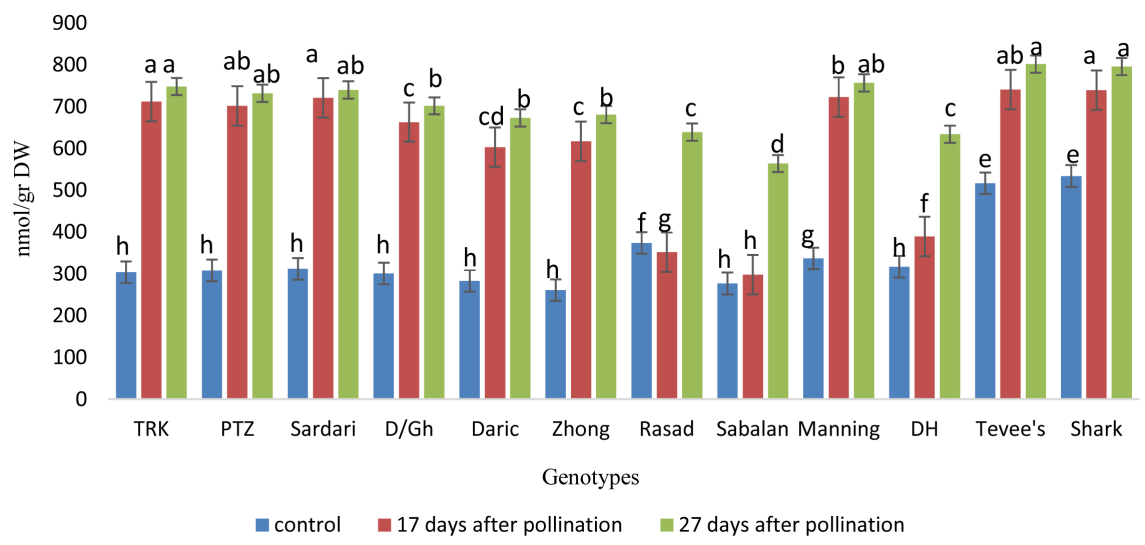

Figure 4. Spermidine content variation in different wheat genotypes under the drought stress condition after pollination.

Table 2. Variability in polyamine contents for six drought-resistant genotypes under drought stress condition after pollination.

\begin{tabular}{|c|c|c|c|c|}
\hline Genotypes & Drought Stress & Putrescine & Spermine & Spermidine \\
\hline & Control & $321 \mathrm{c}$ & $\mathrm{d} 22 / 8$ & $304 \mathrm{f}$ \\
\hline \multirow[t]{3}{*}{ TRK } & 17 days after pollination & $357 \mathrm{~b}$ & a27/7 & $712 \mathrm{a}$ \\
\hline & 27 days after pollination & a411 & c27/7 & $748 \mathrm{a}$ \\
\hline & Control & $316 c$ & $\operatorname{de} 21 / 5$ & $308 \mathrm{f}$ \\
\hline \multirow[t]{3}{*}{ PTZ } & 17 days after pollination & $341 \mathrm{~b}$ & $\mathrm{ab} / 626$ & $702 \mathrm{~b}$ \\
\hline & 27 days after pollination & 389 a & $\mathrm{d} / 622$ & $732 \mathrm{a}$ \\
\hline & Control & $324 \mathrm{c}$ & $\mathrm{d} 22 / 2$ & $312 \mathrm{f}$ \\
\hline \multirow[t]{3}{*}{ Sardari } & 17 days after pollination & $353 \mathrm{~b}$ & $\mathrm{a} / 428$ & $721 \mathrm{a}$ \\
\hline & 27 days after pollination & $393 \mathrm{a}$ & $\mathrm{bc} / 724$ & $740 \mathrm{a}$ \\
\hline & Control & $307 \mathrm{~d}$ & $\mathrm{~d} 22 / 4$ & $301 \mathrm{f}$ \\
\hline \multirow[t]{3}{*}{$\mathrm{D} / \mathrm{Gh}$} & 17 days after pollination & $323 \mathrm{c}$ & $\mathrm{b} / 325$ & $663 c$ \\
\hline & 27 days after pollination & $377 \mathrm{ab}$ & $\mathrm{c} 23 / 1$ & $702 \mathrm{~b}$ \\
\hline & Control & $297 \mathrm{~d}$ & $\mathrm{e} 20 / 7$ & $283 \mathrm{~g}$ \\
\hline \multirow[t]{3}{*}{ Daric } & 17 days after pollination & $309 \mathrm{~d}$ & $\mathrm{~b} / 725$ & $603 \mathrm{~d}$ \\
\hline & 27 days after pollination & $371 \mathrm{ab}$ & $\mathrm{de} / 721$ & $673 c$ \\
\hline & Control & $274 \mathrm{e}$ & $\operatorname{de} 21 / 2$ & $261 \mathrm{~g}$ \\
\hline \multirow[t]{2}{*}{ Zhong } & 17 days after pollination & $299 \mathrm{~d}$ & $a b / 326$ & $617 \mathrm{~d}$ \\
\hline & 27 days after pollination & $359 \mathrm{~b}$ & $22 / \mathrm{v} \mathrm{c}$ & $681 \mathrm{~b}$ \\
\hline
\end{tabular}

${ }^{*}$ Letters above the numbers indicate the significance of mean differences for a significance level of 0.01 .

mine. Spermidine has a role in cell division of developing seeds as well. Moreover, the increase in the concentration of this polyamine under drought stress condition showed that spermidine might have influence on preserving the integrity and subcellular compartments as well as stabilizing the cell division process under drought stress, resembling the spermine. 
Variance analysis of spermine characteristic led to believe that there is a significant difference at 0.05 level among main effects of drought stress, genotype and their interaction (Table 2). Contrasting the means of interaction between drought stress treatments and genotypes revealed that exerting drought stress and giving a rise to its intensity during different phases of wheat plant development induced a continuous rise in spermine content in the genotypes of the study during the first and second phases of sampling (17 and 27 days after pollination), Figure 5.

The results, furthermore, showed that the variability of spermine contents differed among the whole genotypes of the study. The highest amounts of spermine concentration in the whole genotypes of the study occurred in the cell division phase of the seeds (17 days after pollination), nevertheless, the amount of spermine concentration in manning semi-resistant genotype and resistant genotypes were significantly higher than in other genotypes. In summary, the highest spermine content which happened in 17 days after pollination belonged to manning semi-resistant genotype, Figure 5.

$\mathrm{Ma}$ [23] studied the variability trend of spermine content in various wheat cultivars and noticed that the highest concentration of spermine happens in the initial phases of grain development, thereafter, the concentration drops [26]. Additionally, considering the rise in the spermine concentration in initial phase of grain development under drought condition, spermine might have a role in reserving the stability of cell division process in developing seeds.

The increase in spermine content of developing manning semi-resistant genotypes inhibited the decrease in grain yield by inhibiting the decrease in cell division and, subsequently, grain sink size. The increase in the spermine in cell division process of drought-resistant genotypes, however, was not sufficient to inhibit the decrease in grain sink size. Taking into consideration the role of polyamines in preserving the viability and integrity of the membrane and subcellular compartments [27], and, probably, enzyme activities, there might be a correlation between the rise in the grain yield of manning semi-resistant genotype and the rise in the spermine concentration.

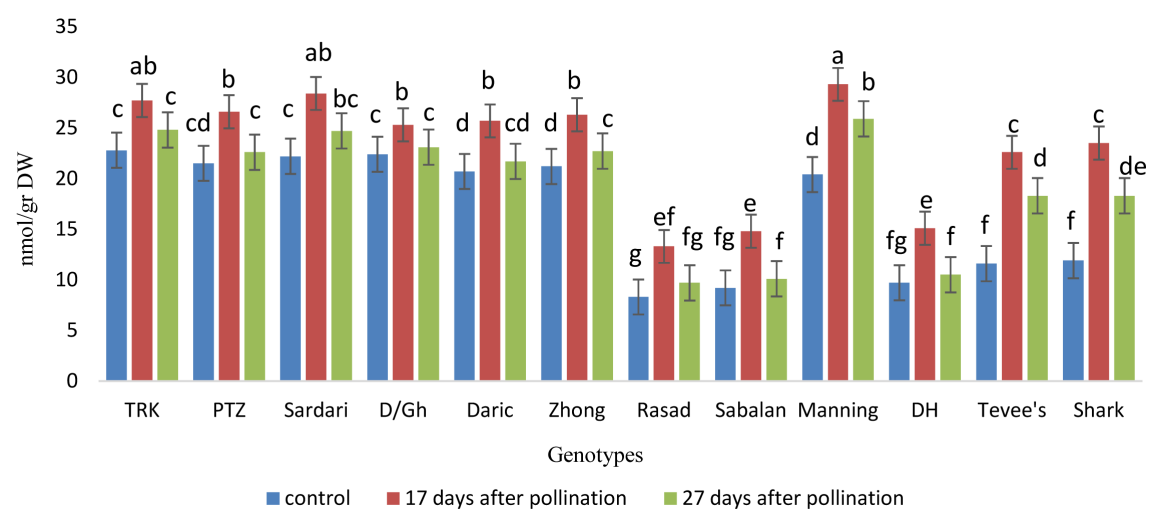

Figure 5. Spermine content variation in different wheat genotypes under the drought stress condition after pollination. 
Variance analysis results for putrescine characteristic indicated that there is significant difference at 0.05 level among genotype and drought stress treatments and their interaction (Table 2). Comparing the mean of drought stress and genotype showed that exerting drought stress and giving a rise to its intensity in the last stages of wheat plant development brought about a continuous rise in putrescine content of genotypes studied (Figure 6). Additionally, results revealed that the trend of variability of putrescine in the resistant genotypes of the study, i.e. TRK, PTZ, Sardari, D/GH, Daric and Zhong, had a gradual increase with the increase in drought stress. However, in the other genotypes of the study a sharp increase in putrescine content with a quite higher putrescine content were registered (Figure 6).

Contrasting the means gave the idea that putrescine content is dependent upon the intensity of stress and the genotype itself. There were found a significant difference among the genotypes under typical irrigation, and all the resistant genotypes, except Zhong genotypes, had the most putrescine contents. In the second phase of sampling (17 days after pollination), resistant genotypes of TRK, Sardari and Manning semi-resistant genotypes had the most putrescine content in comparison with the other genotypes. However, in the last phase of sampling (27 days after pollination) the most increase in putrescine content was observed in Manning semi-resistant genotype, and the rise in putrescine content of sensitive and semi-resistant genotypes was outstanding in comparison with resistant genotypes (Figure 6).

Assessing polyamine contents in resistant-genotypes which were under drought stress condition, after pollination, revealed that the stress induced continuous rise in all the polyamines (putrescine, spermidine and spermine), Table 3. Putrescine content (putrescine $>$ spermidine $>$ spermine) was higher than spermine and spermidine contents for all the drought-resistant genotypes under typical irrigation condition. Under drought stress, after pollination, spermidine content had higher increase in comparison with putrescine and spermine, giving the idea that drought-resistant genotypes have tendency to accumulate much more spermidine rather than other polyamines under such stressful conditions

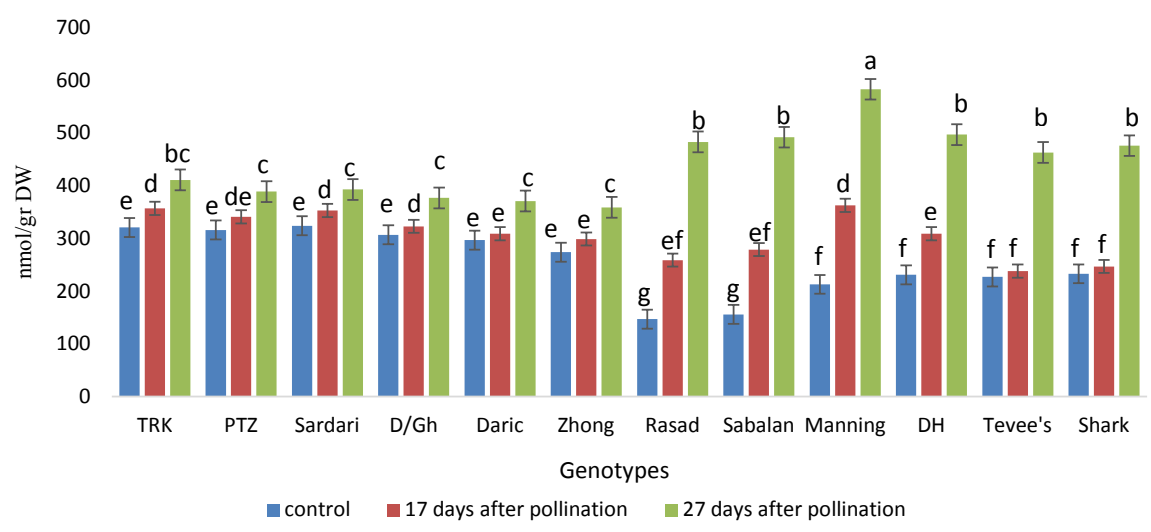

Figure 6. Putrescine content variation in different wheat genotypes under the drought stress condition after pollination. 
Table 3. Variability in polyamine contents for four drought-semi-resistant genotypes under drought stress condition after pollination.

\begin{tabular}{|c|c|c|c|c|}
\hline Genotypes & Drought Stress & Putrescine & Spermine & Spermidine \\
\hline & Control & $147 \mathrm{e}$ & $8 / 3$ e & $374 \mathrm{~d}$ \\
\hline \multirow[t]{3}{*}{ Rasad } & 17 days after pollination & $259 \mathrm{~d}$ & $13 / 3 \mathrm{~d}$ & $352 \mathrm{~d}$ \\
\hline & 27 days after pollination & $483 \mathrm{~b}$ & $9 / 7 \mathrm{e}$ & $639 \mathrm{~b}$ \\
\hline & Control & $156 \mathrm{e}$ & $9 / 2 \mathrm{e}$ & $277 \mathrm{e}$ \\
\hline \multirow[t]{3}{*}{ Sabalan } & 17 days after pollination & $279 \mathrm{~d}$ & $14 / 8 \mathrm{~d}$ & $298 \mathrm{e}$ \\
\hline & 27 days after pollination & $492 \mathrm{~b}$ & $10 / 1 \mathrm{e}$ & $564 c$ \\
\hline & Control & $213 \mathrm{~d}$ & $20 / 4 \mathrm{c}$ & $337 \mathrm{~d}$ \\
\hline \multirow[t]{3}{*}{ Manning } & 17 days after pollination & $363 c$ & $29 / 3 \mathrm{a}$ & $723 \mathrm{a}$ \\
\hline & 27 days after pollination & $583 \mathrm{a}$ & $25 / 9 b$ & $757 \mathrm{a}$ \\
\hline & Control & $231 \mathrm{~d}$ & $9 / 7 \mathrm{e}$ & $317 \mathrm{~d}$ \\
\hline \multirow[t]{2}{*}{$\mathrm{DH}$} & 17 days after pollination & $309 c$ & $15 / 1 \mathrm{~d}$ & $389 \mathrm{~d}$ \\
\hline & 27 days after pollination & $497 \mathrm{~b}$ & $10 / 5 \mathrm{e}$ & $634 \mathrm{~b}$ \\
\hline
\end{tabular}

${ }^{\star}$ Letters above the numbers indicate the significance of mean differences for a significance level of 0.01 .

(Table 3). The reduction in the concentration of putrescine in drought-resistant genotypes under drought stress might be due to its transformation into spermine and spermidine, considering the fact that putrescine is a precursor to spermine and spermidine [25]. Furthermore, it was observed that under the typical irrigation and drought stress condition 17 and 27 days, after pollination, the spermine content of resistant genotypes was higher than spermine content of sensitive and semi-resistant genotypes of the study (see Table 2-4).

Substantial rise in spermidine content was observed in semi-resistant genotypes in comparison with other polyamines when the severity of drought stress was increased. The putrescine was the second while the lowest amount of polyamines was observed in spermine (Table 3 ). In addition, drought-semi-resistant genotypes had higher amount of spermidine under both typical irrigation and drought stress conditions, after 17 and 27 days of pollination. Accordingly, these genotypes have the tendency to accumulate spermidine, analogous to drought-resistant genotypes.

Continuous rise in the putrescine, spermine and spermidine content was observed in the drought-sensitive genotypes. The spermidine content was higher in comparison with putrescine and spermine, under both typical irrigation and drought stress conditions. The putrescine was second to the spermidine and the lowest amount of polyamines was observed in spermine.

This finding suggests that sensitive genotypes used in the study have a tendency to accumulate much more spermidine under harsh drought stress (Table 4). Moreover, accumulated putrescine in drought-semi-resistant and -sensitive genotypes under various level of drought stress of the study was higher when is compared with other genotypes (see Tables 2-4). 
Table 4. Variability in polyamine contents for two drought-sensitive genotypes under drought stress condition after pollination.

\begin{tabular}{ccccc}
\hline Genotypes & Drought Stress & Putrescine & Spermine & Spermidine \\
\hline \multirow{3}{*}{ Tevee's } & Control & $227 \mathrm{a}$ & $11 / 6 \mathrm{c}$ & $517 \mathrm{c}$ \\
& 17 days after pollination & $238 \mathrm{~b}$ & $22 / 6 \mathrm{a}$ & $741 \mathrm{~b}$ \\
& 27 days after pollination & $463 \mathrm{a}$ & $18 / 3 \mathrm{~b}$ & $802 \mathrm{a}$ \\
\multirow{2}{*}{ Shark } & Control & $233 \mathrm{~b}$ & $11 / 9 \mathrm{c}$ & $534 \mathrm{c}$ \\
& 17 days after pollination & $247 \mathrm{~b}$ & $23 / 5 \mathrm{a}$ & $739 \mathrm{~b}$ \\
& 27 days after pollination & $476 \mathrm{a}$ & $18 / 3 \mathrm{~b}$ & $796 \mathrm{a}$ \\
\hline
\end{tabular}

${ }^{*}$ Letters above the numbers indicate the significance of mean differences for a significance level of 0.01 .

The findings of the study point out that sensitive and semi-resistant genotypes have small influence on putrescine metabolism and its transformation under drought stress into spermine and spermidine; consequently, the putrescine concentration in genotypes arises. Liu et al. measured the differences among putrescine concentration in leaves of the drought-sensitive and -tolerant wheat cultivars and noticed that under the drought stress condition, the putrescine concentration in the leaves of sensitive cultivars significantly increases in comparison with tolerant cultivars [21].

Other studies showed that variability in polyamine contents happens due to the reaction to various environmental stresses [21] [28]. Additionally, they showed that the putrescine content of genotypes increases under stress conditions. Putrescine is a precursor of gamma-Aminobutyric which acts as a signal after the onset of stress [29]. In 2004, Liu et al. noticed that using drought stress on wheat seedling causes significant change in polyamine concentration in the leaves of sensitive and tolerant genotypes. Under such circumstances, the tolerant genotypes showed higher amounts of spermine and spermidine in their leaves than putrescine, whereas putrescine content in sensitive genotypes had a considerable rise. $\mathrm{Ma}$ [23] pointed out that decrease in amount of putrescine and increase in spermine and spermidine contents of seedlings leaves of stress-tolerant wheat genotypes improve the viability of protoplast under unfavorable environmental condition. Silveira [30] noticed that compared to putrescine content, the amount of spermine and spermidine were increased gradually during the stage of grain development, while they were working on assessing the polyamine contents of Pinus taeda L. grain development. Their observations revealed that the amount of free polyamines in grain development stage was higher than amount of other bound polyamines, whereas in the stage of seed maturity, free spermine content was high and other types of bound polyamines were not observed. In another experiment, Ma [23] worked on the modification of polyamines with calcium ion and found that the highest amount of spermine in wheat seeds accumulates in during milk stage. Spermine accumulation under the experiment circumstances was not correlated with the relative amount of water in leaves nor the environmental changes such as rainfall, ambient temperature and sunlight, rather, the amount of spermine, under such circumstances, was 
regulated by the calcium ion.

In 2007, Yang et al. studied 6 different rice cultivars with different drought tolerance in order to assess the effect of drought stress on polyamine content of the seeds [26]. The results of the study were included of the change in the biosynthetic contents and polyamine contents. Moreover, the results revealed an increase in the content of spermine and spermidine in resistant, tolerant and sensitive cultivars. The resistant cultivars have the highest amount of putrescine content, whereas the amount of putrescine content in the sensitive cultivars were lowest and the maximum variability was observed in sensitive cultivars.

The spermidine content in the resistant genotypes was increased much more than the increase in spermine and putrescine content. Researchers believe that the shortfall of putrescine content in resistant genotypes accounts for rapid transformation of the putrescine into other polyamines [31]. In effect, the higher amount of putrescine at the onset of drought stress is a requisite for rapid transformation into other polyamines. Be that as it may, high amount of putrescine is poisonous for cells [31].

\section{Conclusions}

In this study, polyamines content of all genotypes which were studied under drought stress increased, and the highest increase in putrescine content under drought stress happened in semi-resistant genotypes. In addition, the highest increase in spermine content under the drought stress condition happened in resistant genotypes, and the highest increase in spermidine content happened in sensitive genotypes.

The increase in concentration of spermine and spermidine under the influence of drought stress condition during different grain development stages might be due to their effect on the viability of cell division and their unique role on stability of membrane, nucleic acids and other organelles.

The excess in the concentration of spermine and spermidine of manning genotype seeds under drought stress condition might inhibit the decrease in grain filling and bring about a delay in senescence of the plant via protecting cells, and subsequently, cause higher function of manning genotypes in comparison with other genotypes.

According to the study, semi-resistant genotype of manning seems to be capable of having high function under the drought stress condition by means of preserving high amounts of polyamine inside the seeds. Nevertheless, the amount of polyamines does not seem to be the sole main and determining factor of continuous function of manning in semi-resistant genotypes, and its role has to be taken under consideration with other physiological characteristics and has to be studied further and more accurately.

\section{References}

[1] Li, X., Cai, J., Liu, F., Dai, T., Cao, W. and Jiang, D. (2014) Cold Priming Drives the 
Sub-Cellular Antioxidant Systems to Protect Photosynthetic Electron Transport against Subsequent Low Temperature Stress in Winter Wheat. Plant Physiology and Biochemistry, 82, 34-43.

[2] Farooq, M., Basra, S.M.A., Wahid, A. and Rehman, H. (2009) Exogenously Applied Nitric Oxide Enhances the Drought Tolerance in Fine Grain Aromatic Rice (Oryza sativa L.). Journal of Agronomy and Crop Science, 195, 254-261.

https://doi.org/10.1111/j.1439-037X.2009.00367.x

[3] Liu, F., Shahnazari, A., Andersen, M.N., Jacobsen, S.E. and Jensen, C.R. (2006) Physiological Responses of Potato (Solanum tuberosum L.) to Partial Root-Zone Drying: ABA Signalling, Leaf Gas Exchange, and Water Use Efficiency. Journal of $E_{X-}$ perimental Botany, 57, 3727-3735. https://doi.org/10.1093/jxb/erl131

[4] Wei, L., Wang, L., Yang, Y., Wang, P., Guo, T. and Kang, G. (2015) Abscisic Acid Enhances Tolerance of Wheat Seedlings to Drought and Regulates Transcript Levels of Genes Encoding Ascorbate-Glutathione Biosynthesis. Frontiers in Plant Science, 6, 458. https://doi.org/10.3389/fpls.2015.00458

[5] Li, X., Jiang, H., Liu, F., Cai, J., Dai, T., Cao, W. and Jiang, D. (2013) Induction of Chilling Tolerance in Wheat during Germination by Pre-Soaking Seed with Nitric Oxide and Gibberellin. Plant Growth Regulation, 71, 31-40.

https://doi.org/10.1007/s10725-013-9805-8

[6] Farooq, M., Wahid, A., Kobayashi, N., Fujita, D. and Basra, S.M.A. (2009) Plant Drought Stress: Effects, Mechanisms and Management. Agronomy for Sustainable Development, 29, 185-212. https://doi.org/10.1051/agro:2008021

[7] Kaur-Sawhney, R., Tiburcio, A.F., Atabella, T. and Gaston, A.W. (2003) Polyamines in Plants: An Overview. Journal of Cell Molecular Biology, 2, 1-12.

[8] Kusano, T., Yamaguchi, K., Berberich, T. and Takahashi, Y. (2007) Advances in Polyamine Research in 2007. Journal of Plant Research, 120, 345-350. https://doi.org/10.1007/s10265-007-0074-3

[9] Liu, K., Fu, H.H., Bei, Q.X. and Luan, S. (2000) Inward Potassium Channel in Guard Cells as a Target for Polyamine Regulation of Stomatal Movements. Plant Physiology, 124, 1315-1325. https://doi.org/10.1104/pp.124.3.1315

[10] Liu, J.-H., Kitashiba, H., Wang, J., Ban, Y. and Moriguchi, T. (2007) Polyamines and Their Ability to Provide Environmental Stress Tolerance to Plants. Plant Biotechnology, 24, 117-126. https://doi.org/10.5511/plantbiotechnology.24.117

[11] Pang, X.M., Zhang, Z.Y., Wen, X.P., Ban, Y. and Moriguchi, T. (2007) Polyamines, All-Purpose Players in Response to Environment Stresses in Plants. Plant Stress, 1, 173-188.

[12] Kubis, J. and Krzywanski, Z. (1989) The Dynamics of Polyamines Accumulation in Spring Wheat Leaves during Increasing Water Stress. Acta Physiologiae Plantarum, 11, 157-164.

[13] Zhang, K. and John, P.C.L. (2005) Raised Level of Cyclin Dependent Kinase after Prolonged Suspension Culture of Nicotiana plumbaginifolia Is Associated with More Rapid Growth and Division, Diminished Cytoskeleton and Lost Capacity for Regeneration: Implications for Instability of Cultured Plant Cells. Plant Cell Tissue and Organ Culture, 82, 295-308. https://doi.org/10.1007/s11240-005-1542-x

[14] Malabika, R. and Wu, R. (2001) Arginine Decarboxilase Transgene Expression and Analysis of Environmental Stress Tolerance in Transgenic Rice. Plant Science, 160, 869-875.

[15] Bouchereau, A., Aziz, A., Larher, F. and Martin-Tanguy, J. (1999) Polyamines and 
Environmental Challenges: Recent Development. Plant Science, 140, 103-125.

[16] Groppa, M.D., Benavides, M.P. and Tomaro, M.L. (2003) Polyamine Metabolism in Sunf Lower and Wheat Leaf Discs under Cadmium or Copper Stress. Plant Science, 161, 481-488.

[17] Rider, J.E., Hacker, A., Mackintosh, C.A., Pegg, A.E., Woster, P.M. and Casero, R.A. (2007) Spermine and Spermidinemediate Protection against Oxidative Damage Caused by Hydrogen Peroxide. Amino Acids, 33, 231-240. https://doi.org/10.1007/s00726-007-0513-4

[18] Yamaguchi, K., Takahashi, Y., Berberich, T., Imai, A., Takahashi, T., Michael, A.J. and Kusano, T. (2007) A Protective Role for the Polyamine Spermine against Drought Stress in Arabidopsis. Biochemical and Biophysical Research Communications, 352, 486-490.

[19] Duan, J.J., Li, J., Guo, S.R. and Kang, Y.Y. (2008) Exogenous Spermidine Affects Polyamine Metabolism in Salinity-Stressed Cucumis sativus Roots and Enhances Short-Term Salinity Tolerance. Journal of Plant Physiology, 165, 1620-1635.

[20] Cuevas, J.C., Lopez-Cobollo, R., Alcazar, R., Zarza, X., Koncz, C., Altabella, T., et al. (2008) Putrescine Is Involved in Arabidopsis Freezing Tolerance and Cold Acclimation by Regulating ABA Levels in Response to Low Temperature. Journal of Plant Physiology, 148, 1094-1105. https://doi.org/10.1104/pp.108.122945

[21] Liu, H.H., Dong, B.H., Zhang, Y.Y., Liu, Z.P. and Liu, Y.L. (2004) Relationship between Osmotic Stress and the Levels of Free, Conjugated and Bound Polyamines in Leaves of Wheat Seedlings. Plant Science, 166, 1261-1267.

[22] Ehdaie, B., Alloush, G.A., Madore, M.A. and Wanies, J.G. (2006) Genotypic Variation for Stem Reserves and Mobilization in Wheat. I: Post Anthesis Changes in Internode Dry Matter. Crop Science, 46, 735-746. https://doi.org/10.2135/cropsci2005.04-0033

[23] Ma, R., Zhang, M., Li, B., Du, G., Wang, J. and Chen, J. (2005) The Effects of Exogenous $\mathrm{Ca}^{2+}$ on Endogenous Polyamine Levels and Drought-Resistant Traits of Spring Wheat Grown under Arid Conditions. Journal of Arid Environments, 63, 177-190.

[24] Wang, R.Y., Yu, Z.W. and Pan, Q.M. (1999) Changes of Endogenous Plant Hormone Contents during Grain Development in Wheat. Acta Agronomy Sinica, 25, 227-231.

[25] Abdoli, M. and Saeidi, M. (2012) Using Different Indices for Selection of Resistant Wheat Cultivars to Post Anthesis Water Deficit in the West of Iran. Annals of Biology Research, 3, 1322-1333.

[26] Kuehn, G.D. and Phillips, G.C. (2005) Roles of Polyamines in Apoptosis and Other Recent Advances in Plant Polyamines. Critical Rev. Plant Science, 24, 123-130. https://doi.org/10.1080/07352680590953161

[27] Yang, J., Zhang, J., Huang, Z., Zhu, Q. and Wang, L. (2007) Remobilization of Carbon Reserves Is Improved by Controlled Soil-Drying during Grain Filling of Wheat. Crop Science, 40, 1645-1655. https://doi.org/10.2135/cropsci2000.4061645x

[28] Groppa, M.D. and Benavides, M.P. (2008) Polyamines and Abiotic Stress: Recent Advances. Amino Acids, 34, 35-45. https://doi.org/10.1007/s00726-007-0501-8

[29] Nambeesan, S., AbuQamar, S., Laluk, K., Mattoo, A.K., Mickelbart, M.V., Ferruzzi, M.G., Mengiste, T. and Handa, A.K. (2012) Polyamines Attenuate Ethylene-Mediated Defense Responses to Abrogate Resistance to Botrytis cinerea in Tomato. Plant Physiology, 1033-1045. https://doi.org/10.1104/pp.111.188698 
[30] Silveira, V., Tiago, S.B., Claudete, S.C., Eny, I.S., Miguel, P., Guerra, H. and Walter, H. (2004) Biochemical Changes during Grain Development in Pinus teada L. Plant Growth Regulation, 44, 147-156. https://doi.org/10.1023/B:GROW.0000049410.63154.ed

[31] Yamaguchi, K., Takahash, I.Y., Berberich, T., Imai, A., Miyazaki, A., Takahashi, Michael, A. and Kusano, T. (2006) The Polyamine Spermine Protects against High Salt Stress in Arabidopsis thaliana. FEBS Letters, 580, 6783-6788.

\section{Scientific Research Publishing}

Submit or recommend next manuscript to SCIRP and we will provide best service for you:

Accepting pre-submission inquiries through Email, Facebook, LinkedIn, Twitter, etc. A wide selection of journals (inclusive of 9 subjects, more than 200 journals)

Providing 24-hour high-quality service

User-friendly online submission system

Fair and swift peer-review system

Efficient typesetting and proofreading procedure

Display of the result of downloads and visits, as well as the number of cited articles Maximum dissemination of your research work

Submit your manuscript at: http://papersubmission.scirp.org/

Or contact ojg@scirp.org 